\title{
Incidence of Helicobacter Pylori Infections in a group of patients in Erbil City, Kurdistan Region, Iraq and Its Association with Gastritis and Adenocarcinoma
}

\section{Tavga Hushiar Salim \\ Hawler Medical University}

Salah Tofik Jalal Balaky ( $\sim$ sbalaky2013@gmail.com )

Hawler Medical University https://orcid.org/0000-0001-7694-7303

\section{Rafal Al-Rawi}

Hawler Medical University

Saman Salah eldeen Abdulla

Hawler Medical University

Ahang Hasan Mawlood

Hawler Medical University

Nazar Jawhar

University of Ninevah

Research article

Keywords: Helicobacter pylori, Histopathology, gastric adenocarcinoma, gastritis.

Posted Date: May 8th, 2020

DOI: https://doi.org/10.21203/rs.3.rs-25271/v1

License: (c) (1) This work is licensed under a Creative Commons Attribution 4.0 International License.

Read Full License 


\section{Abstract}

Background: Adenocarcinoma is one of the most common causes of Gastric cancer related deaths worldwide. Helicobacter pylori is the causative agent of most cases of gastritis, it can cause chronic active gastritis and known as a risk factor for the development of gastric cancer. This study aimed to assess the prevalence of $H$. pylori among patients with symptoms of dyspepsia and other gastritis related symptoms and its association with adenocarcinoma.

Methods: This study was carried out during the period of January 2018 to October 2019 with a total of 227 patients with gastritis related symptoms. The presence of H. pylori was detected by Rapid Urease Test (RUT) and histo-pathological tests using biopsy specimens. Statistical Analysis was done by using Chi-square test. $\mathrm{P}<0.05$ was considered to be statistically significant.

Results: From the total of 227 patients with gastritis related symptoms, 26 cases (13.61\%) were diagnosed with adenocarcinoma. Their ages were between 13 and 90 years with mean of $47.81 \pm 18.23$. The result showed that low severity prevalence of $H$. pylori was highest (111 cases) compared to 17 and 63 cases for high and moderate severity, respectively. Comparison between positive low, moderate, and high $H$. pylori cases for rapid urease test was highly significant $(P<0.000)$. The results showed no association between $H$. pylori severity across various age groups and gender. Moreover, goodness of fit test for metaplasia, activity, glandular atrophy, and endoscopic finding across severity status of $H$. pylori showed highly significant. Four composite categorized groups were initiated based on positive/negative prevalance of $\mathrm{H}$. pylori and adenocarcinoma status. Results revealed statistical significance between combination of $H$. pylori and adenocarcinoma with inflammation, lymphoid aggregate, metaplasia, activity of neutrophils, glandular atrophy, rapid urease test, and endoscopic findings.

Conclusion: Histopathology tests are reliable diagnostic tools for the detection of H. pylori. Data showed that $\mathrm{H}$. pylori was seen more in middle age patients with mucosal lymphoid follicle formation and more than one third of patients with adenocarcinoma. Therefore, screening of these infections is an important strategy for preventing gastric adenocarcinoma.

\section{Background}

The discovery of Helicobacter pylori (H. pylori) in 1982 was the starting point of a revolution concerning the concepts and management of gastroduodenal diseases. ${ }^{1,2} \mathrm{H}$. pylori represents one of the most common and medically important infections worldwide. ${ }^{3}$ Chronic infection due to this pathogen is now believed to account for the majority of cases of chronic gastritis. ${ }^{4}$ In addition, $H$. pylori is the major cause of gastric carcinogenesis and other gastric diseases, such as duodenal and gastric non-ulcer dyspepsia, gastroduodenal ulcers, and gastric mucosa-associated lymphoid tissue lymphoma. ${ }^{1,5}$ In recent years, a variety of extra digestive disorders, including cardiovascular diseases, liver diseases and autoimmune disorders have also been associated with infections caused by H. pylori. ${ }^{6}$ Gastric cancer is the third most common cause of death caused and related to cancer worldwide. H. pylori infection is the most known 
risk factor for the development of gastric cancer. The pathogen can cause chronic active gastritis and atrophic gastritis by producing persistent acute-on-chronic inflammation. ${ }^{7}$ The high association of $H$. pylori infections with precancerous gastric lesions led to the pathogen being recognized as a class I carcinogen by the WHO in $1994 .{ }^{8}$ It has also been reported that in a meta-analysis infections, caused by H. pylori, results in a 2- to 3 -fold increase in the risk of gastric cancer. ${ }^{9} \mathrm{It}$ is estimated that approximately $75 \%$ of the gastric cancer burden in the world is attributed to $H$. pylori-induced inflammation. ${ }^{10}$

This study aimed to assess the prevalence of $H$. pylori among patients with symptoms of dyspepsia and other gastritis related symptoms. It also aimed to investigate the association between $\mathrm{H}$. pylori with adenocarcinoma.

\section{Methods}

This study was conducted in the Histopathology laboratory of PAR Private Hospital, Erbil, Iraq, within the period of January 2018 to October 2019. A total of 227 Patients were included of any age and gender with symptoms of gastritis. A questionnaire regarding the age, gender and whether they were taking any dyspepsia related medications was included. The urea breath test was used first to detect $H$. pylori, in which the principle of the test is the pathogen can produce an enzyme called urease, which breaks urea down into ammonia and carbon dioxide. During the test, a tablet containing urea is swallowed and the amount of exhaled carbon dioxide is measured. This indicates the presence of $\mathrm{H}$. pylori in the stomach (BreathTek® UBT for H. pylori kit was used). Three biopsy specimens from the antrum and the corpus were taken and sent for histopathologic study. In the histopathological unit, the biopsy specimens of patients were fixed in $10 \%$ buffered formalin for at least $12 \mathrm{hrs}$, and then embedded in paraffin wax. Hematoxylin and Eosin ( $\mathrm{H}$ and $\mathrm{E}$ ) staining was performed on tissue sections of each case. Three sections for each specimen were de-paraffinized and hydrated in descending grades of alcohol, cut in sequential 4$\mu \mathrm{m}$ sections. The sections were then stained with $\mathrm{H}$ and $\mathrm{E}$ stain to determine the presence of $H$. pylori and gastritis. The H. pylori were clearly detected as curved bacilli on the surface of the gastric epithelial cells. The slides were evaluated by histopathologist and assigned to each morphological variable. The histopathology was used to confirm gastritis and neoplastic conditions found during endoscopy.

A total of 191 Patients with $H$. pylori gastritis were divided into three groups according to the H. pylori severity status of infections (high, moderate and low). Data were categorized as follows: Age years: $\leq 35$, 35-60, > 60; Gender: male, female; Inflammation: mild, moderate, severe; lymphoid aggregate: positive, negative; metaplasia: positive, negative; activity: presence, absence of neutrophils; glandular atrophy: positive, negative; rapid urease test: positive, negative; endoscopic finding: nodular, granular, and erosive; clinical manifestation: pain, IDA (Iron deficiency anemia), dyspepsia, and others (chronic non bloody diarrhea and dysphagia).

The positive and negative results of $H$. pylori infection were categorized together with poor and moderate grades adenocarcinoma status according to the age group, gender and different diagnosis variables \{positive H. pylori/ moderate grade differentiated adenocarcinoma (positive / moderate), positive $H$. 
pylori/ poor grade differentiated adenocarcinoma (positive/ poor), negative H. pylori/ moderate grade differentiated adenocarcinoma (negative/ moderate) and negative H. pylori / poor grade differentiated adenocarcinoma (negative / poor)\}.

\section{Statistical Analysis}

All variables of the patients were entered into Excel worksheet and data analysis was performed using Chi-square independence test, via contingency tables (Statistical Package for the Social Sciences software, SPSS Inc., Chicago, IL, USA). As Chi-square test for $2 \times 3,3 \times 3$ or $3 \times 4$ contingency tables did not support calculation when zero exists as a cell value. Therefore, a goodness of fit (differences between observed and expected cases) was performed using GraphPad Software. ${ }^{11}$ The $P$ value less than 0.05 was considered to be statistically significant.

\section{Results}

The minimum age of the 227 patients was 13 years, maximum age was 90 years and mean age was $47.81 \pm 18.23$. Furthermore, the minimum, maximum and mean age of the 191 infected patients with $H$. pylori based on the categorized severity of the $H$. pylori into high, moderate and low is presented in Table 1. The low state prevalence of $H$. pylori was highest (111 cases) compared to 17 and 63 cases for high and moderate severity of $H$. pylori, respectively. This result showed that cases with no detectable infection were $36(15.86 \%)$ out of the 227 patients.

Table 1

Age distribution across severity status of $\mathrm{H}$. pylori.

\begin{tabular}{|llll|}
\hline severity of $H$. pylori & High & Moderate & Low \\
(Number of cases), (\%) & $(17),(8.9 \%)$ & $(63),(32.98 \%)$ & $(111),(58.12 \%)$ \\
\hline Age (yrs): min. & 16 & 13 & 18 \\
Max. & 57 & 86 & 90 \\
Average & $38.59 \pm 13.13$ & $45.56 \pm 18.26$ & $47.72 \pm 18.03$ \\
\hline
\end{tabular}

Results revealed that all patients had positive rapid urease test and no association between $H$. pylori severity across various age groups $(P=0.245)$, and gender $(P<0.961)$. It was noticed that high prevalence of $H$. pylori was most likely to occur in patients of 35-60 years old $(43.98 \%)$ compared to younger or older ages $(30.89,25.13 \%)$, respectively (Table 2). The prevalence of $H$. pylori infection was $50.26 \%$ in males $49.74 \%$ in females showing similar distribution of $H$. pylori among the gender. The result showed a statistical significant association between $H$. pylori severity across various Inflammation $(P<0.001)$, and Lymphoid aggregate $(P<0.001)$. Chi square for diagnosis variables of metaplasia, activity which represented by presence or absence of neutrophils, glandular atrophy, rapid urease test, endoscopic finding, and clinical manifestation were highly significant $(P<0.001)$ across low, moderate, and high $H$. pylori severity (Fig. 1). 
The moderate Inflammation was recorded the highest (71.2\%) compared to mild (25.66\%) and severe (3.14\%). The finding of the positive lymphoid aggregate showed $82.72 \%$ compared to $17.28 \%$ of the negative tests (Fig. 2).

On the other hand, positive metaplasia was found in $11.52 \%$; neutrophils in $17.8 \%$ and positive tests for glandular atrophy in $9.95 \%$ of cases.

The distribution of the endoscopic findings showed $64.92 \%$ nodular, whereas $35.08 \%$ were erosive. Clinical manifestation of most patients (56.02\%) had pain, $10.47 \%$ had IDA, $16.75 \%$ had dyspepsia, and $16.75 \%$ had other clinical manifestations. 
Table 2

Distribution of $\mathrm{H}$. pylori according to the variables studied.

\begin{tabular}{|c|c|c|c|c|c|}
\hline $\begin{array}{l}\text { H. pylori } \\
\text { (Number of cases) }\end{array}$ & No. (\%) & $\begin{array}{l}\text { High } \\
\text { (17) }\end{array}$ & $\begin{array}{l}\text { Moderate } \\
\text { (63) }\end{array}$ & $\begin{array}{l}\text { Low } \\
\text { (111) }\end{array}$ & $\begin{array}{l}P \\
\text { Value }\end{array}$ \\
\hline Age years: $\leq 35$ & $59(30.89)$ & 6 & 22 & 31 & $0.245^{*}$ \\
\hline $35-60$ & $84(43.98)$ & 10 & 24 & 50 & \\
\hline$>60$ & $48(25.13)$ & 1 & 17 & 30 & \\
\hline Gender. & $96(50.26)$ & 8 & 32 & 56 & $0.961 *$ \\
\hline Male & $95(49.74)$ & 9 & 31 & 55 & \\
\hline \multicolumn{6}{|l|}{ Female } \\
\hline \multirow{3}{*}{$\begin{array}{l}\text { Inflammation: } \\
\text { mild } \\
\text { moderate } \\
\text { severe }\end{array}$} & $49(25.66)$ & 1 & 8 & 40 & $0.001 *$ \\
\hline & \multirow{2}{*}{$\begin{array}{l}136 \\
(71.20) \\
6(03.14)\end{array}$} & 15 & 51 & 70 & \\
\hline & & 1 & 4 & 1 & \\
\hline \multirow[t]{2}{*}{ Lymphoid aggregate: positive negative } & \multirow{2}{*}{$\begin{array}{l}158 \\
(82.72) \\
33(17.28)\end{array}$} & 17 & 60 & 81 & 0.001 \\
\hline & & 0 & 3 & 30 & \\
\hline Metaplasia : positive & $22(11.52)$ & 4 & 4 & 14 & 0.001 \\
\hline Negative & $\begin{array}{l}169 \\
(88.48)\end{array}$ & 13 & 59 & 97 & \\
\hline \multirow{2}{*}{$\begin{array}{l}\text { Activity: } \\
\text { presence of neutrophils } \\
\text { absence of neutrophils }\end{array}$} & \multirow{2}{*}{$\begin{array}{l}157 \\
(82.20) \\
34(17.80)\end{array}$} & 17 & 57 & 83 & 0.001 \\
\hline & & 0 & 6 & 28 & \\
\hline \multirow[t]{2}{*}{ Glandular atrophy: positive Negative } & $19(09.95)$ & 0 & 3 & 16 & 0.001 \\
\hline & $\begin{array}{l}172 \\
(90.05)\end{array}$ & 17 & 60 & 95 & \\
\hline \multirow[t]{2}{*}{ Rapid Urease Test: positive Negative } & $191(100)$ & 17 & 63 & 111 & 0.001 \\
\hline & $0(0)$ & 0 & 0 & 0 & \\
\hline \multirow[t]{3}{*}{ Endoscopic finding: nodular granular erosive } & $28(14.66)$ & 2 & 12 & 14 & 0.001 \\
\hline & $96(50.26)$ & 7 & 25 & 64 & \\
\hline & $67(35.08)$ & 8 & 24 & 35 & \\
\hline
\end{tabular}




\begin{tabular}{|c|c|c|c|c|c|}
\hline $\begin{array}{l}\text { H. pylori } \\
\text { (Number of cases) }\end{array}$ & No. (\%) & $\begin{array}{l}\text { High } \\
\text { (17) }\end{array}$ & $\begin{array}{l}\text { Moderate } \\
(63)\end{array}$ & $\begin{array}{l}\text { Low } \\
\text { (111) }\end{array}$ & $\begin{array}{l}P \\
\text { Value }\end{array}$ \\
\hline \multirow[t]{4}{*}{$\begin{array}{l}\text { Clinical manifestation: pain IDA dyspepsia } \\
\text { others }\end{array}$} & $\begin{array}{l}107 \\
(56.02)\end{array}$ & 10 & 41 & 56 & \multirow[t]{4}{*}{0.012} \\
\hline & $20(10.47)$ & 3 & 4 & 13 & \\
\hline & $32(16.75)$ & 3 & 13 & 16 & \\
\hline & $32(16.75)$ & 1 & 5 & 26 & \\
\hline
\end{tabular}

A total of 26 patients out of the total 227 were diagnosed as gastric adenocarcinoma. The 26 cases were categorized based on poor or moderate adenocarcinoma together with positive or negative for the presence H. pylori. Four composite groups were initiated: positive H. pylori / moderate grade adenocarcinoma (positive / moderate), positive H. pylori / poor grade adenocarcinoma (positive / poor), negative H. pylori / moderate grade adenocarcinoma (negative / moderate) and negative H. pylori / poor grade adenocarcinoma (negative / poor) with 4, 6, 5 and 11 cases, respectively (Table 3, Fig. 3).

Results presented in Table 3 revealed highly statistically significant $(P<0.001)$ difference in the number of cases in each category (combinations) of $H$. pylori and adenocarcinoma with Inflammation, lymphoid aggregate, metaplasia, activity of neutrophils, glandular atrophy, and endoscopic, and rapid urease test. On the other hands, age, gender, and clinical manifestation presence or absent showed no significant associations. 
Table 3

Distribution of combination of $\mathrm{H}$. pylori and adenocarcinoma according to the variables studied.

\begin{tabular}{|c|c|c|c|c|c|}
\hline $\begin{array}{l}\text { H. pylori /adenocarcinoma } \\
\text { (Number of cases) }\end{array}$ & $\begin{array}{l}\text { positive/ } \\
\text { moderate } \\
\text { (4) }\end{array}$ & $\begin{array}{l}\text { positive } \\
\text { poor } \\
\text { (6) }\end{array}$ & $\begin{array}{l}\text { negative/ } \\
\text { moderate (5) }\end{array}$ & $\begin{array}{l}\text { negative } \\
\text { / poor } \\
\text { (11) }\end{array}$ & $\begin{array}{l}P \\
\text { value }\end{array}$ \\
\hline Age years: $\leq 35^{\star \star}$ & 0 & 0 & 0 & 2 & $0.333^{*}$ \\
\hline $35-60$ & 3 & 1 & 2 & 4 & \\
\hline$>60$ & 1 & 5 & 3 & 5 & \\
\hline Gender: Male & 3 & 5 & 4 & 7 & $0.814 *$ \\
\hline Female & 1 & 1 & 1 & 4 & \\
\hline Inflammation: negative & 0 & 0 & 2 & 10 & 0.001 \\
\hline \multirow[t]{3}{*}{ mild moderate severe } & 4 & 4 & 0 & 0 & \\
\hline & 0 & 2 & 0 & 0 & \\
\hline & 0 & 0 & 3 & 1 & \\
\hline Lymphoid aggregate: & 0 & 2 & 0 & 0 & 0.001 \\
\hline positive negative & 4 & 4 & 5 & 11 & \\
\hline Metaplasia : & 0 & 2 & 0 & 0 & 0.001 \\
\hline positive Negative & 4 & 4 & 5 & 11 & \\
\hline Neutrophils: presence & 2 & 2 & 0 & 0 & 0.001 \\
\hline Absence & 2 & 4 & 5 & 11 & \\
\hline Glandular atrophy: & 3 & 4 & 0 & 0 & 0.010 \\
\hline positive Negative & 1 & 2 & 5 & 11 & \\
\hline \multirow{2}{*}{$\begin{array}{l}\text { Rapid Urease Test: positive } \\
\text { Negative }\end{array}$} & 4 & 6 & 0 & 0 & 0.001 \\
\hline & 0 & 0 & 5 & 11 & \\
\hline \multirow{2}{*}{$\begin{array}{l}\text { Endoscopic finding: nodule (mass) } \\
\text { erosive lesion }\end{array}$} & 1 & 2 & 3 & 8 & $0.001 *$ \\
\hline & 3 & 4 & 2 & 3 & \\
\hline Clinical signs: & 3 & 4 & 2 & 4 & $0.443^{*}$ \\
\hline pain with melena Others & 1 & 2 & 3 & 7 & \\
\hline
\end{tabular}


Similarly, it can be seen that lymphoid aggregate status (positive vs. negative tests) has similar trends across $\mathrm{H}$. pylori severity status (Fig. 5). Both positive and negative lymphoid aggregate showed lowest values (17 and 0 , respectively) for high $H$. pylori and both diagnostic tests increased to 60 and 3 cases for the moderate $H$. pylori status, then both attained the peak cases of their lines when $H$. pylori status was low(81 and 30, respectively). Such similar trend plots indicate a high significant statistical positive association.

Table 3, Figs. 6 and 7 illustrate highly statistically significant $(P<0.001)$ findings between a combination of positive and negative $H$. pylori and poor or moderate adenocarcinoma with rapid urease test, and glandular atrophy. Figure 6 shows fluctuations in number of cases among categorization (combination) of $\mathrm{H}$. pylori and adenocarcinoma with rapid urease test, which represent an inverse association, as the trend of the positive rapid urease test line has opposite direction and magnitude of the negative rapid urease test line. The positive rapid urease test line increased from 4 to 6 then declined to 0,0 for (positive / moderate), (positive / poor), (negative / moderate) and (negative / poor), respectively. Whereas, negative rapid urease test line increased from 0,0 to 5 then to 11 for (positive / moderate), (positive / poor), (negative / moderate) and (negative / poor), respectively.

Similarly, Fig. 7 shows fluctuations in number of cases among categorization (combination) of $H$. pylori and adenocarcinoma with positive and negative glandular atrophy, which represent inverse association, as the trend of the positive glandular atrophy line has opposite direction and magnitude of the negative glandular atrophy line. The negative glandular atrophy line increased from 1 to 2 then to 5 and 11 for (positive / moderate), (positive / poor), (negative / moderate) and (negative / poor), respectively. Whereas, positive glandular atrophy line increased from 3, to 4 then declined to 0,0 for (positive / moderate), (positive / poor), (negative / moderate) and (negative / poor), respectively.

\section{Discussion}

The prevalence of $H$. pylori differs both between and within countries, with high rates of infection being associated with low socioeconomic status and high densities of living. ${ }^{12}$ When endoscopy is clinically indicated, the test of first choice is the urease test on an antral-biopsy specimen. ${ }^{13}$ In the current study, the minimum age of the 227 patients was 13 years and the maximum age was 90 years, with mean age of $47.81 \pm 18.23$. High prevalence of $H$. pylori was most likely to occur in patients of $35-60$ years old (43.98\%) compared to younger or older ages $(30.89,25.13 \%)$, respectively. The result of this study shows that the prevalence of $H$. pylori infection found in male was $50.26 \%$ and in females was $49.74 \%$, this is similar to the distribution of $H$. pylori among the gender in patients studied in Nepal. Where among 2820 eligible patients, males were $54.2 \%$ and females were $45.8 \%$ with the mean age of 46.3 years \pm 17.6 ranging from 8 to 94 years. ${ }^{14}$ On the other hand, in a large French cross-sectional study, a significantly lower prevalence of $H$. pylori infection was observed in females as compared with males. ${ }^{15}$

Several studies were conducted in Kurdistan dealing with prevalence of $H$. pylori and gastritis. Research result indicated that the prevalence of $H$. pylori in total of 310 samples (170 male and 140 female) were 
$39.4 \%$. The prevalence of $H$.pylori in the age between $41-50$ years were $(51.2 \%)$, followed by patients with age $>61$ years $(46.5 \%)$. The rate of infection among females were $(40.7 \%)$, compared with males infection rate of (38.2\%). That study concluded that the prevalence of H. pylori in Erbil city was high and the infection occurred at different stages of life. ${ }^{16}$ Other report found that the prevalence of $H$. pylori infection among 311 students ( $57.8 \%$ female and $42.2 \%$ male) increased with age and a higher frequency found in students from low income social status. They also observed that $H$. pylori were highly prevalent among university students in Erbil, being $55.8 \%$ of the 311 students. ${ }^{17}$ Recently, in a study carried out to investigate the seroprevalence of $H$. pylori infection among Cihan University students, Erbil. A total of 197 blood samples were collected from the students (53 females and 144 males), and tested for anti- $H$. pylori antibodies, using a rapid immunochromatography assay. The prevalence of anti- $H$. pylori antibodies is relatively high among students, with no significant differences between male and female in respect to having $H$. pylori infection. It was concluded that both university and public communities should be aware of infections caused by the pathogen such as gastritis, peptic ulcer, and about its potential association with malignant transformation. ${ }^{18}$ Furthermore, investigation of $H$. pylori infection among 190 patients diagnosed with gastric cancer in Sulaimani city indicated that a history of $H$. pylori infection was observed in $63.2 \%$ of the patients and that prevalence of gastric cancer was higher among females (61.5\%), and patients aged over 50 years (73.6\%). ${ }^{19}$ Interestingly a study carried out on 50 patients suffering from stomach cancer in Erbil city and 25 healthy individuals, as a control group showed that the highest number of chromosomal aberrations (Dicentric chromosome) occurred in the fifth age group (65-74). It also shown that most patients are males in the age group (45-64), most of whom smoked and drank alcohol and were infected with H. pylori. ${ }^{20}$

The present study also revealed statistically significant associations between $\mathrm{H}$. pylori and adenocarcinoma with inflammation, glandular atrophy, and rapid urease test. Furthermore, results revealed highly statistically significant $(P<0.001)$ differences among categorization (combination) of $H$. pylori and adenocarcinoma with inflammation, lymphoid aggregate, metaplasia, activity of neutrophils, glandular atrophy, endoscopic, and rapid urease test. The result also indicated that 26 cases out of 227 cases $(13.61 \%)$ were diagnosed to have adenocarcinomia, and that 10 out of 26 adencarcinoma cases (about 38.5\%) showed positive rate of $\mathrm{H}$. pylori infection. Similar result of low rate of gastric cancer incidence was noted with high prevalence of H. pylori infection in India, Philippines, or Thailand; on the other hand, the high rate of gastric cancer incidence was observed in Japan and Korea with variable prevalence of $H$. pylori. ${ }^{21-23}$ It was suggested that $H$. pylori infection is not the only factor related to gastric cancer risk. ${ }^{24,25}$ Furthermore, Individuals with chronic $H$. pylori infection have an increased risk of acquiring a adenocarcinoma, $26,27,28$ as the pathogen indicated as a carcinogen associated with gastric adenocarcinoma. ${ }^{29}$ Colonization of stomach by $\mathrm{H}$. pylori can result in gastritis, and may have a risk of developing peptic ulcers (Kusters et al., 2006), it is notable that in this study $35.08 \%$ of the H. pylori gastritis revealed erosion. The National Institutes of Health consensus conference in the United States declared an association between H. pylori and peptic ulcer disease. ${ }^{30,31}$ 
Data produced from this study showed that low density of $H$. pylori was highest ( 111 cases) compared to 17 and 63 cases for high and moderate density infections, respectively. H. pylori caused chronic gastritis

in all colonized subjects. This can lead to peptic ulcer disease, atrophic gastritis, gastric adenocarcinoma, and MALT (mucosa-associated lymphoid tissue) lymphoma. ${ }^{32}$ Patients with current $H$. pylori infection have a higher risk of developing gastric cancer compared with patients with past infection or eradication history of $H$. pylori because the eradication of $H$. pylori reduces the risk of gastric cancer. It was reported that the successful treatment of $H$. pylori decreases the risk of developing gastric cancer by approximately 3 fold. ${ }^{33}$ Therefore, screening and treatment of $H$. pylori is an important strategy for preventing gastric cancer in high-risk populations, particularly among societies.

This study has a number of limitations. The generalizability of the findings is limited as samples were collected only from one city (Erbil), this suggests that the study population might not be representative of the general $H$. pylory infections in Kurdistan region. The sample size of this study is relatively small for a region with a high burden of the disease as the diagnosed patients are only from one city of the region in Iraq.

\section{Conclusion}

The histopathology and RUT tests are reliable invasive diagnosis for $H$. pylori. It was noticed that $H$. pylori seen more in middle age group patients living in Erbil ,Kurdistan with mucosal lymphoid follicle formation, moderate active inflammatory changes as well as $H$. pylori seen in more than one third of patients with adenocarcinoma cases. So screening, follow up and treatment of $H$. pylori is an important strategy for preventing gastric adenocarcinoma in Erbil, Kurdistan.

\section{List Of Abbreviations}

H. pylori: Helicobacter pylori, RUT: Rapid Urease Test, WHO: World Health Organization, $\mathrm{H}$ and E: Hematoxylin and Eosin, IDA: Iron deficiency anemia, SPSS: Social Sciences software,

\section{Declarations}

Acknowledgments: The authors would like to thank the management and staff at PAR Private Hospital for the help and provision of access to Technical resources available there.

\section{Authors'contributions:}

TS participated in made substantial contributions to the conception and design of the study.

SB have made substantial contributions to the design of the study and submitting the draft.

RA have drafted the work and substantively revised it.

SA have made his contribution to the analysis and interpretation of data. 
AM have made her contribution to the design of the study and analysis of data.

NJ have made substantial contributions to the acquisition of data.

All authors have read and approved the submitted version.

Funding: Not applicable.

Availability of data and materials: The Samples used for the current study are available on reasonable request.

Ethics approval and consent to participate: Consents from the study participants were obtained verbally and the study protocol was reviewed and approved by Scientific and Research Ethics Committee of the College of Health Sciences/ Hawler Medical University.

Consent for publication: Not applicable.

Competing interests: The authors declare that they have no competing interests.

\section{Author details:}

1. Medical Microbiology Department, College of Health Sciences, Hawler Medical University, Erbil, Iraq.

2. Department of clinical analysis, College of Pharmacy, Hawler Medical University, Erbil, Iraq.

3. College of Dentistry, Hawler Medical University, Erbil, Iraq.

4. Department of pathology, Medical College, Ninevah University, Iraq

\section{References}

1. Rajan A, Ganguli P, Pathak N, Ranjan A, Thapa R, Tripathi S. Correlation of serology with morphological changes in gastric biopsy of pylori infection. International Journal of Research in Medical Sciences. 2017; 26;5 (5):1851-7.

2. Abu-Sbeih RS, Hawari AD, Hassawi DS, Al-Daghistani HI. Isolation and detection of Helicobacter pylori from patients suffering from peptic ulcer using biochemical tests and molecular techniques. American Journal of Biochemistry \& Biotechnology. 2014; 1:10 (1):58.

3. Akanda MR, Rahman AN. Comparative Study of different methods for detection of Helicobacter pylori in gastric biopsies. Dinajpur Med Col J. 2011; 4(1):1-6.

4. Garg B, Sandhu V, Sood N, Sood A, Malhotra V. Histopathological analysis of chronic gastritis and correlation of pathological features with each other and with endoscopic findings. Polish Journal of Pathology. 2012; 1:63(3):172-8.

5. Lee JY, Kim N. Diagnosis of Helicobacter pylori by invasive test: histology. Annals of translational medicine. 2015; 3(1). 
6. Choi YJ, Kim N, Lim J, Jo SY, Shin CM, Lee HS, Lee SH, Park YS, Hwang JH, Kim JW, Jeong SH. Accuracy of diagnostic tests for Helicobacter pylori in patients with peptic ulcer bleeding. Helicobacter. 2012; 17(2):77-85.

7. Kurt O, Ozturk K, Altun B. Association between Helicobacter pylori and Gastric Cancers. Gut and liver. 2017; 11(2):312-3.

8. Parkin DM, Bray F, Ferlay J, Pisani P. Global cancer statistics, 2002. CA Cancer J Clin. 2005; 55(2):74108.

9. Huang JQ, Sridhar S, Chen Y, Hunt RH. Meta-analysis of the relationship between Helicobacter pylori seropositivity and gastric cancer. Gastroenterology.1998; 114(6): 1169-1179.

10. Amieva M, Peek RM Jr. Pathobiology of Helicobacter pylori-induced gastriccancer. Gastroenterology. 2016; 150(1):64-78.

11. GraphPad Software, Inc.2018.7825 Fay Avenue, Suite 230, La Jolla, CA 92037 USA. (Accessed 2018. at https://www.graphpad.com/scientific-software/prism/).

12. Hazel, M. and M. Francis, 2002. Epidemiology and diagnosis of H. pylori infection. Helicobacter, 7: 816. DOI: 10.1046/j.1523-5378.7.s1.10.x

13. Ruba SA, Azmi DH, Dhia SH, and Hala IA. Isolation and detection of helicobacter pylori from patients suffering from peptic ulcer using biochemical tests and molecular techniques. American Journal of Biochemistry and Biotechnology 10 (1): 58-68, 2014. ISSN: 1553-3468.

14. Umid KS, Arnab G, Vijay MA, Suresh CK. Prevalence of Helicobacter pylori infection, its correlation with gastroduodenal diseases and the incidence of gastric cancer in Nepal. JAIM 2013; 2: 02(04):54. https://www.researchgate.net/publication/258998213. DOI:10.3126/jaim.v2i2.8777.

15. Broutet, N, Sarasqueta AM, Sakarovitch C, Cantet CF, and Lethuaire D, et al., 2001. Helicobacter pylori infection in patients consulting gastroenterologists in France: Prevalence is linked to gender and region of residence. Eur. J. Gastroenterol. Hepatol., 13: 677-684. DOI: 10.1097/00042737-2001060000 .

16. AL-Mashhadany DA, Layla QI, Ahmed MZ. Seroprevalence of helicobacter pylori among human in Erbil governorate, Kurdistan region, Iraq. 2018; RJLBPCS 4(2). 268-280.

17. Hussen BM, Saleem SQ, Halgurd FA and Suha HA. The Prevalence of Helicobacter pylori among University Students in Iraq. Indian Journal of Science and Technology. 2013; 6 (8):5019 -5023.

18. Alsakee HM, Sarah HM, Gulistan HM, Asia SM, llaf AR, Naza khan TS. Prevalence of AntiHelicobacter pylori Antibodies among Students of Cihan University, Erbil. Cihan University-Erbil Scientific Journal. 2019; 3(1):66-70. http://journals.cihanuniversity.edu.iq/index.php/cuesj

19. Mohialdeen FA, Mohammed IMG, Khalid AH, Ahmad RA, Chrakhan JA, Nuha AM, Amir AS, Renwarr RH, Bashdar KA. Distribution of Helicobacter pylori Infection among Gastric Cancer in Hiwa Hospital, Sulaimani City. 2019; Journal of Research in Medical and Dental Science 7(2): 194-196.

20. Sulaiman KM. Cytogenetic study of stomach cancer in Erbil City. ZANCO Journal of Pure and Applied Sciences. 2016; 28 (4): 56-65. http://doi.org/10.21271/ZJPAS.28.4.9 
21. Miwa H, Go MF, Sato N. H. pylori and Gastric Cancer: TheAsian Enigma. Am J Gastroenterol 2002; 97:1106-1112.

22. Yamagata $\mathrm{H}$, Kiyohara $\mathrm{Y}$, Aoyagi $\mathrm{K}$, et al. Impact of Helicobacter pylori infection on gastric cancer incidence in a general Japanese population: the Hisayama study. Arch Intern Med 2000;160:19621968.

23. Malaty HM, Kim JG, Kim SD, et al. Prevalence of Helicobacter pylori infection in Korean children: inverse relation to socioeconomic status despite a uniformly high prevalence in adults. Am J Epidemiol 1996;143:257-262.

24. Nomura A, Stemmermann GN, Chyou PH et al. Helicobacter pylori infection and gastric carcinoma among Japanese-Americans in Hawaii. N Engl J Med 1991; 325:1132-1136.

25. Kikuchi S, Wada O, Nakajima T et al. Serum anti-Helicobacter pylori antibody and gastric carcinoma among young adults. Cancer 1995; 75:2789-2793.

26. Nocturne G, Pontarini E, Bombardieri M, Mariette X. Lymphomas complicating primary Sjögren's syndrome: from autoimmunity to lymphoma. Rheumatology 2019; (Oxford, England).doi:1093/rheumatology/kez052.

27. Abbas H, Niazi M, Makker J. Mucosa-Associated Lymphoid Tissue (MALT) Lymphoma of the Colon: A Case Report and a Literature Review. The American Journal of Case Reports 2017; 18: 49197.doi:12659/AJCR.902843. PMC 5424574. PMID 28469125.

28. Paydas S. Helicobacter pylori eradication in gastric diffuse large B cell lymphoma. World Journal of Gastroenterology 2015; 21(13): 3773-3776.doi: 3748/wjg.v21.i13.3773.

29. IARC Monographs on the evaluation of carcinogenic risks to humans. In: International Agency for Research on Cancer Monograph 61. Lyon: IARC; 1994. Schistosomes, liver flukes and Helicobacter pylori; pp. 177-240.

30. Marshall BJ, Warren JR. Unidentified curved bacilli in the stomach of patients with gastritis and peptic ulceration. Lancet. 1984; 1:1311-1315.

31. NIH Consensus Conference. Helicobacter pylori in peptic ulcer disease. NIH Consensus Development Panel on Helicobacter pylori in Peptic Ulcer Disease. JAMA. 1994; 272:65-69.

32. Malfertheiner P, F Megraud F, O'Morain CA, Gisbert JP, Kuipers EJ, Axon AT, et al. On behalf of the European Helicobacter and Microbiota Study Group and Consensus panel. Management of Helicobacter pylori infection-the Maastricht V/Florence Consensus Report. Online First, published on October 5, 2016 as 10.1136/gutjnl-2016-312288. Copyright Article author (or their employer) 2016. Produced by BMJ Publishing Group Ltd (\& BSG) under licence. http://gut.bmj.com/ on November 17, 2016.

33. Omer K, Kadir O, Battal A. Association between Helicobacter pylori and Gastric Cancers. Gut and Liver 2017; 11: 2 312-313.

\section{Figures}




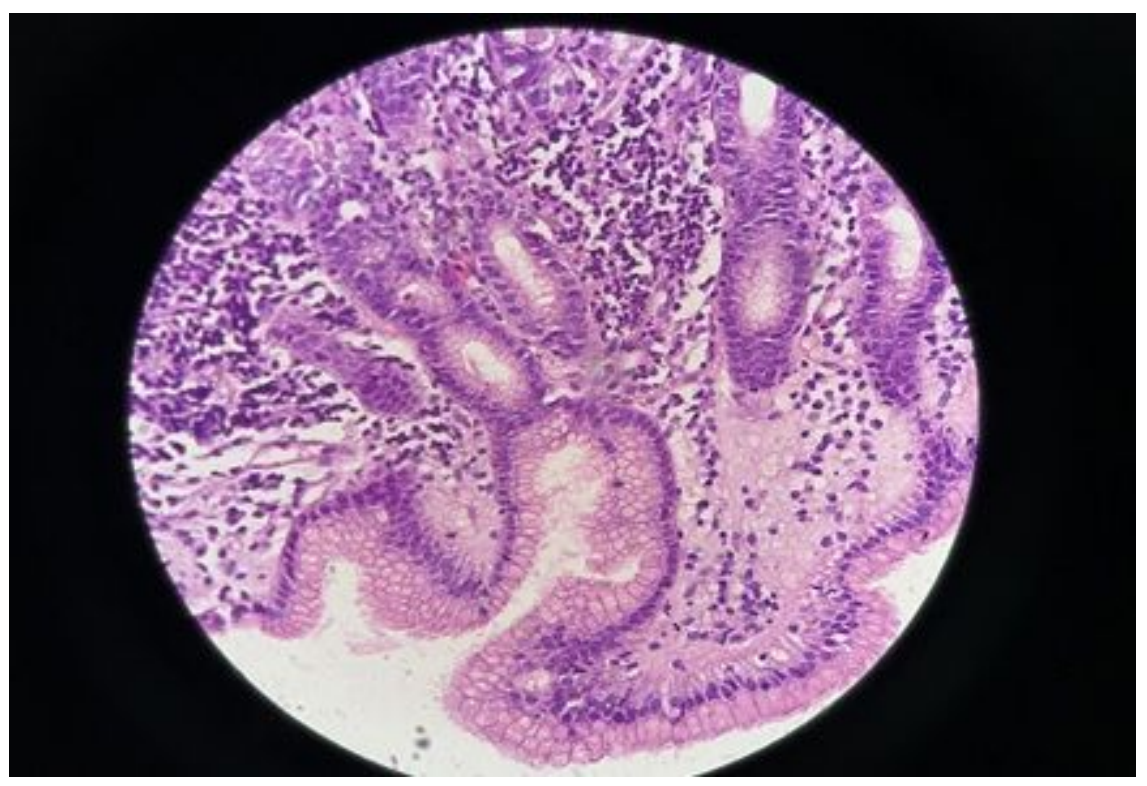

Figure 1

Chronic gastritis with low density of H. pylori. (H\&E stain 400x).

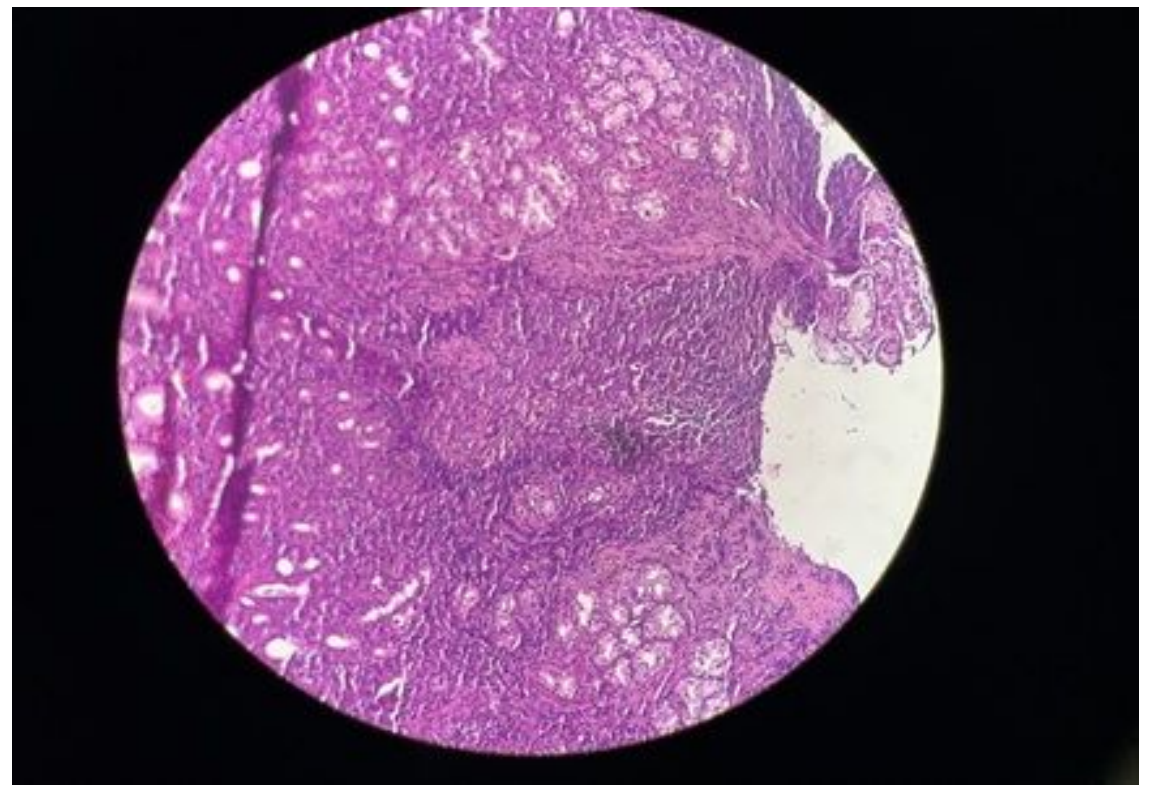

\section{Figure 2}

Chronic gastritis with lymphoid follicle formation. (H\&E stain 400x). 


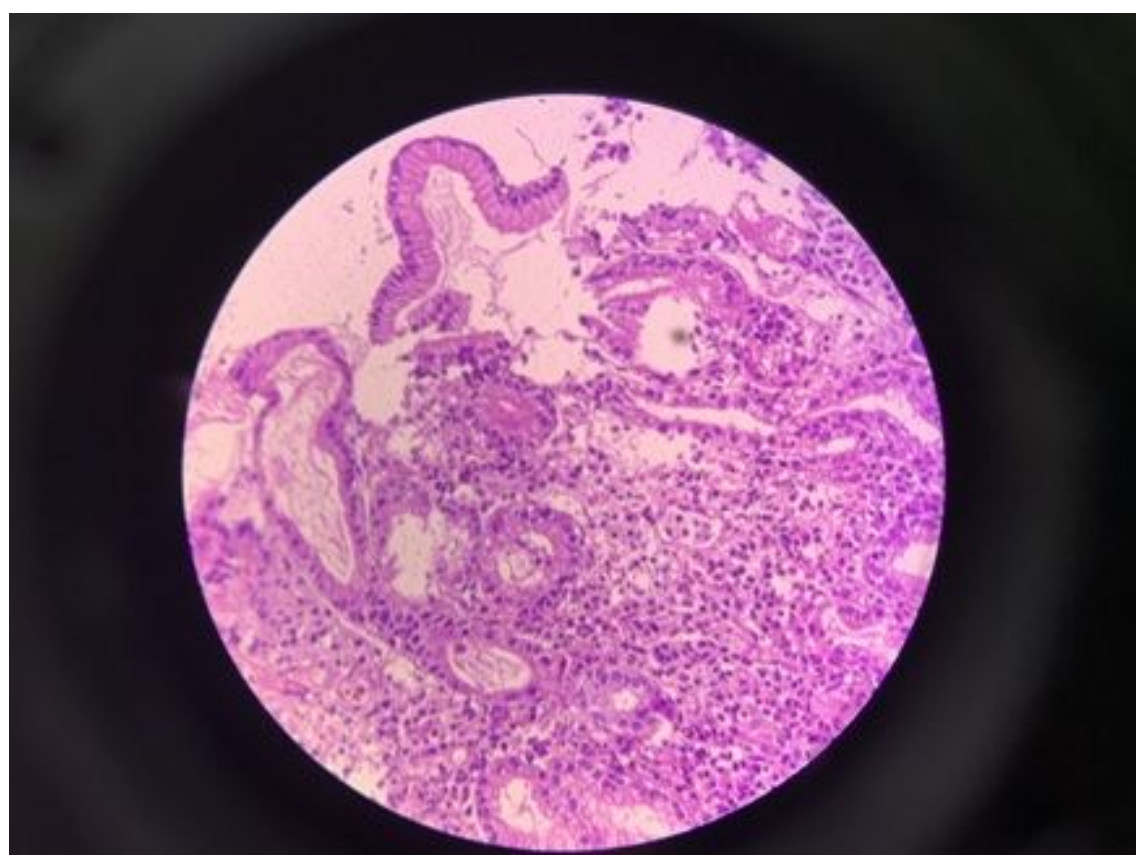

Figure 3

Gastritis adenocarcinoma with low density of H. pylori. (H\&E stain 100x).

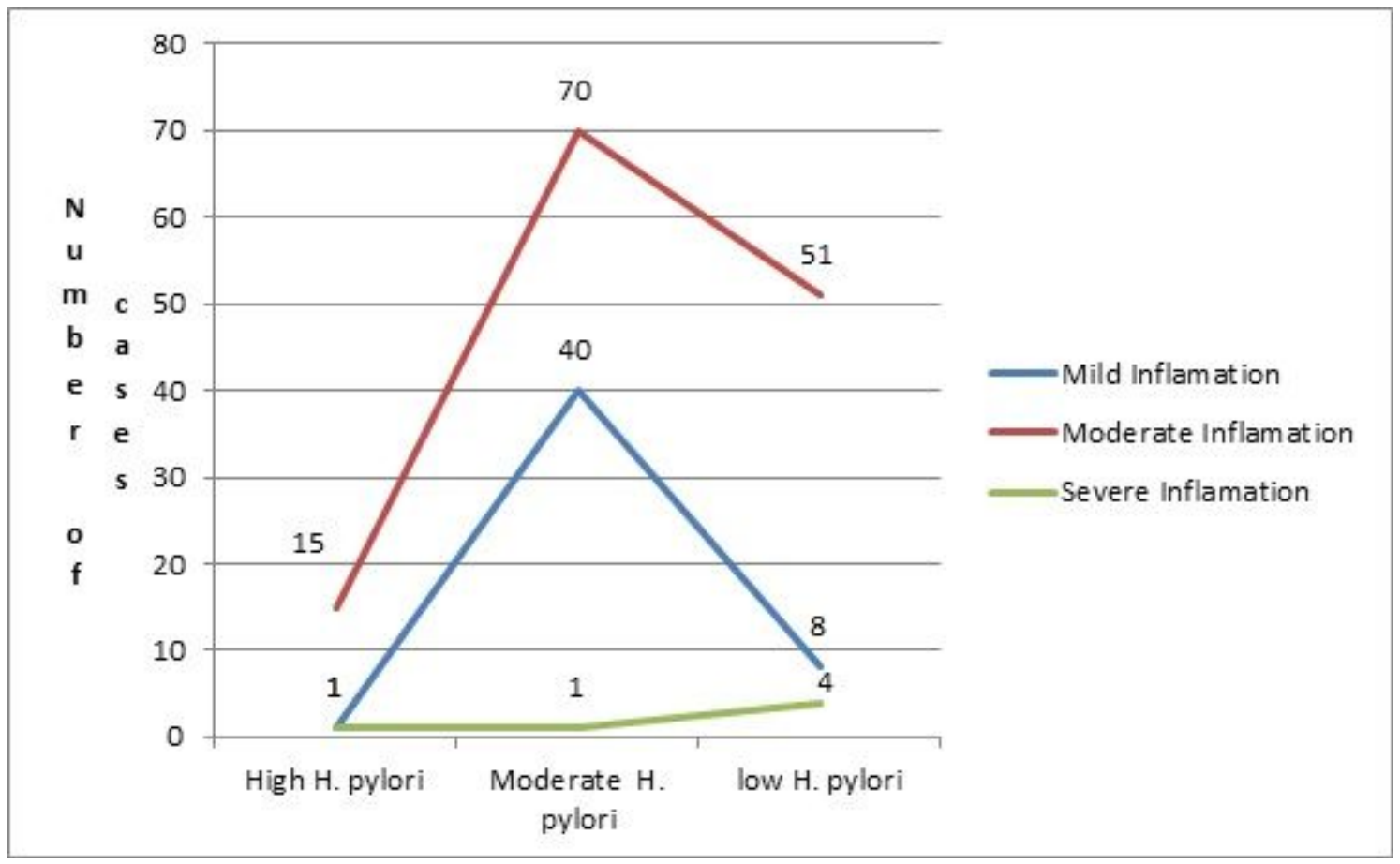

Figure 4

Positive association among severity of $\mathrm{H}$. pylori status with diagnostic inflammation 


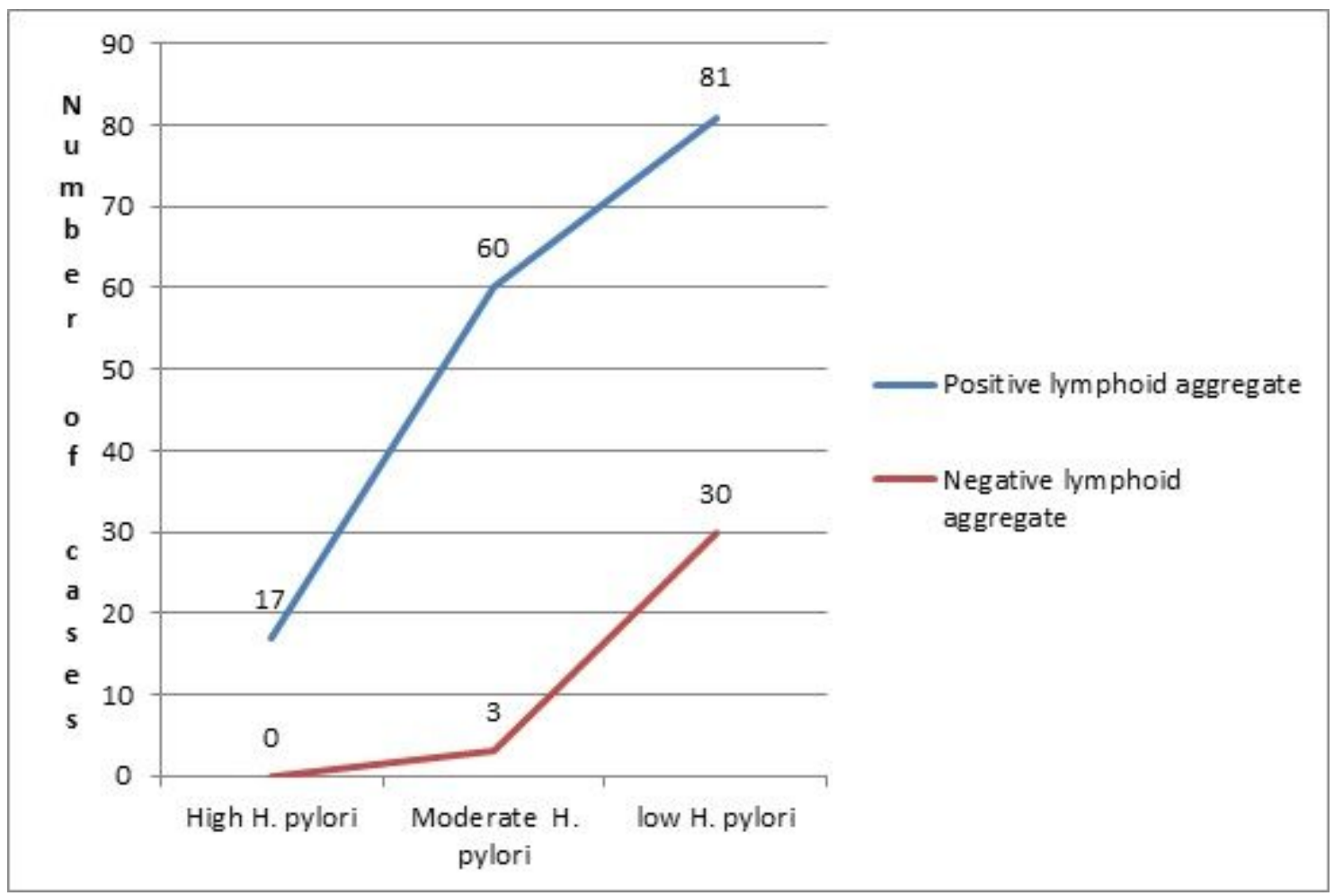

Figure 5

Positive association among severity of $\mathrm{H}$. pylori status with lymphoid aggregate status.

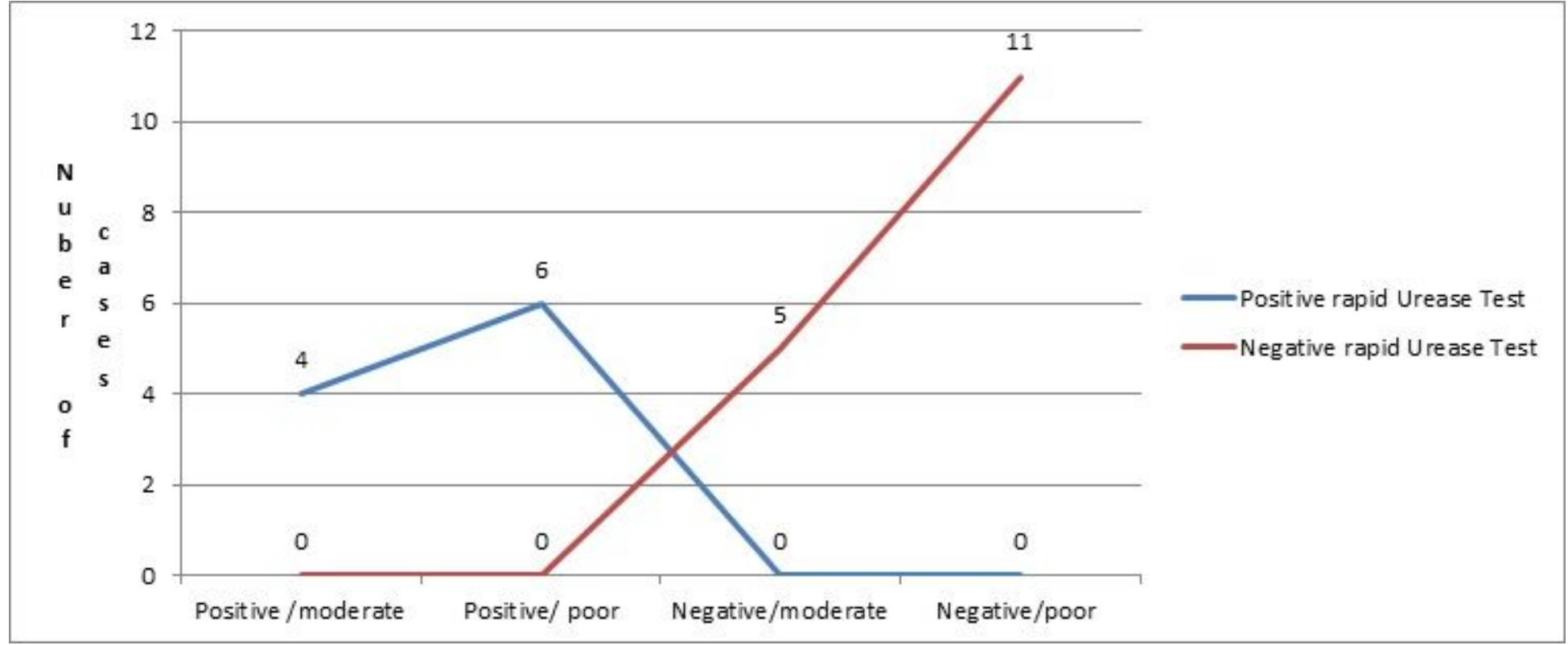

\section{Figure 6}

Inverse association among severity of $\mathrm{H}$. pylori status with rapid urease test. 


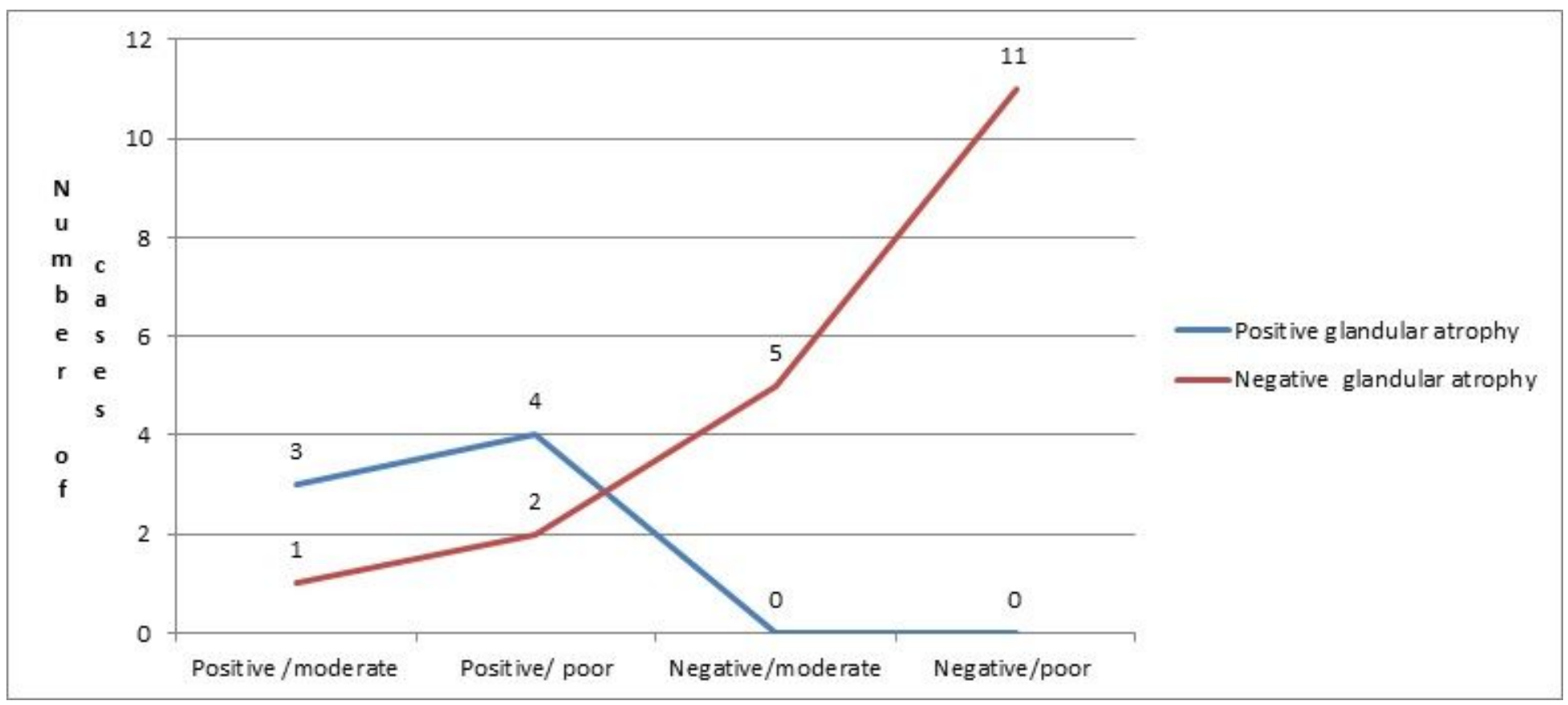

\section{Figure 7}

Inverse association among severity of $\mathrm{H}$. pylori status with glandular atrophy test. 